Homepage: http://epubs.icar.org.in/ejournal/index.php/JWR

\title{
Identification of multiple rust resistant bread wheat genotypes
}

Hanif Khan*, Om Prakash Gangwar, Subhash Chander Bhardwaj, Pramod Prasad, Om Parkash, Chandra Nath Mishra, Raj Kumar, Gopalareddy Krishnappa, Satish Kumar, Sonu Singh Yadav, Prem Lal Kashyap, Sudheer Kumar, Ravish Chatrath and Gyanendra Pratap Singh

ICAR - Indian Institute of Wheat and Barley Research, Karnal Haryana - 132 001, India

Article history: Received: 20 Jan., $2021 \quad$ Revised: 3 April, $202 \quad$ Accepted: 18 April, 2021

Citation: Khan H, OP Gangwar, SC Bhardwaj, P Prasad, O Parkash, CN Mishra, R Kumar, G Krishnappa, S Kumar, SS Yadav, PL Kashyap, S Kumar, R Chatrath and GP Singh. 2021. Identification of multiple rust resistant bread wheat genotypes. Journal of Cereal Research 13(1): 89-93. http://doi.org/10.25174/2582-2675/2021/110307

*Corresponding author: hanif.khan@icar.gov.in

(C) Society for Advancement of Wheat and Barley Research

Key words: APR, Bread wheat, Rust resistant and SRT

Wheat is the staple food and main source of calories in Indian diet and has been under cultivation in the Indian subcontinent since Harrapan civilization. It is a cosmopolitan grain consumed by nearly 2.5 billion people in more than 90 countries and provides $\sim 20 \%$ of the total calories in the human diet (Anonymous, 2020). The ever-increasing population, rapid urbanization, reduction in cultivable area, increased domestic consumption, demands well-planned efforts to face the future challenges of food security of India. Worldwide wheat production is threatened by various biotic and abiotic stresses. Among wheat diseases, three rusts (yellow, brown and black) are major threats due to the rapid appearance of new races (pathotypes) of rust pathogens with additional virulence for the major and widely deployed resistance genes. Yellow (stripe) rust which occurs in comparatively cooler areas can cause yield losses often ranging from 10 to $70 \%$ on susceptible varieties (Chen, 2005), whereas, brown (leaf) rust which is most widely occurring in wheat-growing areas can cause yield losses up to 50 per cent (Bhardwaj et al., 2016). Black (stem) rust although mostly occurs at maturity stage can cause yield losses up to 100 per cent in case of an early start of disease in warmer areas (Prasad et al., 2016).

There are two prevalent ways to control wheat rusts: chemical control and genetic resistance. Wheat rust management using in-built host resistance is preferred keeping in view of economic and environmental concerns faced by farmers of this major cereal crop (Kumar et al.,
2021). Further, continued use of fungicides often results in the development of resistance in rust pathogens to fungicides (Oliver, 2014). The rust diseases have been brought under control primarily by growing resistant varieties. Based on the knowledge of definite host pathogen-interaction, resistance breeding in wheat has become very precise and focused (Bhardwaj, 2013). Although, a large number of resistance genes against three wheat rust diseases have been identified in wheat germplasm (McIntosh et al., 2017; McIntosh et al., 2020), a majority have been defeated by various new and highly virulent pathotypes (Anonymous, 2021). The rapid appearance of new races of rust pathogens with virulence for the many widely deployed rust resistance genes in wheat has led to increased focus on diversification and pyramiding resistance genes in wheat. Recently, the appearance of new highly virulent pathotypes of Puccinia striiformis tritici (Pst) such as 110S119 and 238S119 (Gangwar et al., 2019) and their subsequent spread in entire Northern India has threatened the wheat production and income security of Indian farmers. Most of the rust resistance genes in present day wheat cultivars do not condition resistance when present singly (Khan et al., 2017; Kaur et al., 2016). An adequate level of genetic resistance to all the current rust pathotypes is a major breeding objective in our wheat breeding programmes. Seedling resistance or 'all stage resistance' (ASR), is typically expressed at all growth stages, conferred by a single 'major effect' gene often associated with a hypersensitive response and is often race specific 
(Riaz et al., 2016). Therefore, the present study was carried out to identify all stage resistance (ASR) against three rust diseases in advanced bread wheat lines.

A total of 320 advanced bread wheat lines including some CIMMYT selections were subjected to seedling resistance test (SRT) under controlled environmental conditions (glasshouse) against most prevalent and virulent pathotypes of $P$. striiformis tritici (Pst) (yellow rust), P. triticina (Ptr) (brown rust) and $P$. graminis tritici (Pgt) (black rust) at ICAR-IIWBR, Regional Station, Flowerdale, Shimla, India. Rust susceptible checks such as Agra Local, A-9-30-1, LWH and five check varieties (HD3086, DBW187, DBW90, WH1142 and DBW303) were also used along with test genotypes in each evaluation. The advanced wheat lines were developed using resistant donors which are widely effective and under-utilized through concerted efforts of breeders and pathologists at ICAR-IIWBR, Karnal and its Regional Station, Shimla, India.

Three Pst pathotypes 110S119, 238S119 and 47S103 (T) separately; a mixture of five $P$. triticina pathotypes viz, 77-1, 77-5, 77-9, 12-5 and 104-2, and a mixture of five Pgtpathotypes viz,11, 40A, 21A-2, 117-6 and 122 were used in the SRT study during October-December, 2020. These pathotypes are being maintained at the ICAR-IIWBR, Regional Station Flowerdale, Shimla. Seedlings were grown in aluminum trays which are sufficient enough to accommodate 18 test lines along with a susceptible check. These trays were filled with a mixture of fine loam and farmyard manure (3:1) and maintained in a rust-free greenhouse at $20^{\circ} \mathrm{C}$. Inoculations were performed on one-week old seedlings using uredospores suspended in a light weight, non-phytotoxic mineral oil (Saltrol) using an atomizer. Inoculated seedlings were put in dew chambers with humidity $\geq 80 \%$, and incubated in the dark for 48 hours at $10-12{ }^{\circ} \mathrm{C}$; $18-20{ }^{\circ} \mathrm{C}$; and $20-22{ }^{\circ} \mathrm{C}$ for yellow, brown and black rusts, respectively. Thereafter, seedlings were moved to the temperature-controlled glasshouse at $15-20{ }^{\circ} \mathrm{C}, 20-22{ }^{\circ} \mathrm{C}$ and $22-25^{\circ} \mathrm{C}$ for yellow, brown and black rusts, respectively, following incubation. Rust scoring was done 14-16 days after inoculation using 0 to 4 scale (Stakman et al., 1962). Scores less than 2 were categorized as resistant (R), 2 as moderately resistant (MR), $2+$ to 3 as moderately susceptible (MS) and $3^{+}$and above as susceptible. An individual line was categorized broadly resistant when it showed resistant reaction against all the rust pathotypes used in the present study.

Analysis of host pathogen-interaction revealed that experimental wheat material in SRT was subjected to sufficient level of disease pressure as evident by $3^{+}$score on all the susceptible checks in each set of inoculations. Based upon host-pathogen interaction using multiple rust pathotypes, the wheat lines were characterized for usefulness in the breeding pipeline. Table 1 shows the number of resistant lines to one or the other rust diseases and the percentage of total genotypes. Out of 320 lines, 265 were resistant to one or more rust diseases. Among the remaining 55 genotypes, none was completely susceptible to all the pathotypes. Among the resistant material, 31 genotypes including some sister lines were completely resistant to all the 13 pathotypes of three rust pathogens (Table $1 \& 2$ ). The maximum number of resistant lines were scored against black rust (80 lines). A proportionately higher number (99 lines) were resistant to both brown and black rust diseases. Seventeen lines were resistant against both yellow and black rusts, whereas, seven lines were resistant against both yellow and brown rusts. Only nine genotypes were resistant against yellow rust, whereas 22 genotypes were resistant to brown rust.

Table 1: Number and proportion of genotypes showing resistance to one or more rust disease.

\begin{tabular}{|c|c|c|}
\hline Resistance to & Number of genotypes & Percentage \\
\hline Yellow rust only & 9 & 2.81 \\
\hline Brown rust only & 22 & 6.87 \\
\hline Black rust only & 80 & 25.0 \\
\hline Yellow and brown rust & 7 & 2.19 \\
\hline Yellow and black rust & 17 & 5.31 \\
\hline Brown and black rust & 99 & 30.94 \\
\hline Yellow, brown and black rust & 31 & 9.69 \\
\hline Partial resistance/moderate susceptibility to one or more pathotype & 55 & 17.19 \\
\hline Total & 320 & 100 \\
\hline
\end{tabular}

Details of pedigree information and rust scores of 31 genotypes which were found resistant against all the three rust diseases are provided in Table 2. Important major rust-resistant genes such as $\operatorname{Yr} 10, \operatorname{Yr} 15, \mathrm{Yr} 24$, 
$\operatorname{Lr} 24 / \operatorname{Sr} 24, \operatorname{Lr} 42, \operatorname{Sr} 22, \operatorname{Sr} 26$, and $\operatorname{Sr} 31$ and minor pleiotropic gene $\operatorname{Lr} 34 / \operatorname{Sr} 55 / \operatorname{Yr} 18$ were carried by some of the parental genotypes and are likely inherited in the resistant progenies.

Table 2: Pedigree information and SRT scores of wheat genotypes with complete resistance against all the three rust diseases

\begin{tabular}{|c|c|c|c|c|c|c|}
\hline \multirow[t]{2}{*}{ Genotype } & \multirow[t]{2}{*}{ Pedigree* } & \multicolumn{3}{|c|}{ Pst } & \multirow{2}{*}{$\begin{array}{c}\text { Ptr } \\
\text { Mix } \\
\end{array}$} & \multirow{2}{*}{$\begin{array}{l}P g t \\
\text { Mix }\end{array}$} \\
\hline & & $110 \mathrm{~S} 119$ & $238 \mathrm{~S} 119$ & $\mathrm{~T}$ & & \\
\hline RWP1001 & PBW703 (Yr10+Yr15)/DBW95 & 0 & 0 & 0 & ;- & $2^{=}$ \\
\hline RWP1003 & HSB2949(Yr15+Yr24)/PBW $703(\operatorname{Yr} 10+\operatorname{Yr} 15)$ & 0 & 0 & 0 & 0 & $2^{=}$ \\
\hline RWP1165 & HD2967/PBW698 (Yr10+Yr15) & 0 & 0 & 0 & ;- & 2 \\
\hline RWP1166 & HD2967/PBW698 (Yr10+Yr15) & 0 & ;- & 0 & ;- & 0 \\
\hline RWP1178 & RAJ3765/DPW621-50 & 0 & 0 & 0 & ;- & ;- \\
\hline RWP1186 & PBW703 (Yr10+Yr15)/RV50 (Rht13) & 0 & 0 & 0 & $; 1$ & 0 \\
\hline RWP1187 & PBW703 (Yr10+Yr15)/DBW95 & 0 & 0 & 0 & $; 1$ & $2^{=}$ \\
\hline RWP1191 & PBW698 (Yr10+Yr15)/HD3070 & 0 & 0 & 0 & ;- & $2^{=}$ \\
\hline RWP1197 & HSB2949 (Yr15+Yr24)/PBW703 (Yr10+Yr15) & 0 & 0 & 0 & $;^{-}$ & 0 \\
\hline RWP1216 & 19-20 EPC402 (Sr26) & ; & ; & 0 & $1,2^{+}$ & $2^{=}$ \\
\hline RWP1306 & 52nd IBWSN 1004 & ;- & ;- & 0 & $; 1$ & $2^{=}$ \\
\hline RWP1308 & 52nd IBWSN 1033 & ;- & ;- & 0 & $; 1$ & ; \\
\hline RWP1358 & 14 STEMRRSN 6018 (Sr22) & ;- & 0 & 0 & ;- & 0 \\
\hline RWP1375 & HD2967*2/PBW703 (Yr10+Yr15) & 0 & 0 & 0 & ;- & $2^{=}$ \\
\hline RWP1385 & HD2967*2/PBW703 (Yr10+Yr15) & 0 & 0 & 0 & ;- & $2^{=}$ \\
\hline RWP1386 & HD2967*2/PBW703 (Yr10+Yr15) & 0 & 0 & 0 & ;- & ;- \\
\hline RWP1387 & HD2967*2/PBW703 (Yr10+Yr15) & 0 & 0 & 0 & ;- & ;- \\
\hline RWP1388 & HD3086/PBW703 (Yr10+Yr15) & 0 & 0 & 0 & ;- & ;- \\
\hline RWP1389 & HD3086/PBW703 (Yr10+Yr15) & 0 & 0 & 0 & ; & $2^{=}$ \\
\hline RWP1393 & DBW112/PBW703 (Yr10+Yr15) & 0 & 0 & 0 & ; & $;-$ \\
\hline RWP1396 & DPW621-50/PBW698 (Yr10+Yr15) & 0 & 0 & 0 & ;- & $2^{=}$ \\
\hline RWP1397 & DPW621-50/PBW698 (Yr10+Yr15) & 0 & ;- & 0 & ;- & $2^{=}$ \\
\hline RWP1405 & HD2967/PBW698 (Yr10+Yr15) & 0 & ;- & 2 & ;- & 1,2 \\
\hline RWP1406 & HD2967/PBW703 (Yr10+Yr15) & 0 & 0 & 0 & ; & $2^{=}$ \\
\hline RWP1408 & HD2967/PBW703 (Yr10+Yr15) & 0 & 0 & 0 & ;- & 2 \\
\hline RWP1419 & DBW14/NIAW34//ELLISON & ;- & ; & 0 & ; & ; \\
\hline RWP1420 & RAJ37645/DPW621-50 & 2 & $; 2$ & 0 & ; & 0 \\
\hline RWP1425 & DBW39/FLW26 (Lr42+Yr27) & 0 & 0 & 0 & ;- & ;- \\
\hline RWP1426 & DBW39/FLW26 (Lr42+Yr27) & 0 & 0 & 0 & ;- & ;- \\
\hline RWP1429 & HSB-4 (Yr15)/HI1563 (Lr24/Sr24) & 0 & 0 & 0 & $; 1$ & 0 \\
\hline RWP1443 & DBW112/PBW703 (Yr10+Yr15) & 0 & 0 & 0 & ;- & $2^{=}$ \\
\hline \multicolumn{7}{|c|}{ Susceptible checks } \\
\hline Agra Local & & $3^{+}$ & $3^{+}$ & $3^{+}$ & $3^{+}$ & $3^{+}$ \\
\hline LWH & & $3^{+}$ & $3^{+}$ & $3^{+}$ & $3^{+}$ & $3^{+}$ \\
\hline A9-30-1 & & $3^{+}$ & $3^{+}$ & $3^{+}$ & $3^{+}$ & $3^{+}$ \\
\hline \multicolumn{7}{|l|}{ Check var. } \\
\hline HD3086 & & $33^{+}$ & 0 & 0 & 2,3 & $2^{=}$ \\
\hline DBW187 & & $3^{+}$ & $3^{+}$ & $3^{+}$ & $; 1$ & $2^{+}$ \\
\hline DBW90 & & $3^{+}$ & $33^{+}$ & $3^{+}$ & $3^{+}$ & $3^{+}$ \\
\hline WH1142 & & $3^{+}$ & 3 & 0 & $3^{+}$ & $; 1,2$ \\
\hline DBW303 & & $3^{+}$ & $3^{+}$ & 0 & 2,3 & $2^{=}$ \\
\hline
\end{tabular}

*Resistance gene mentioned in the pedigree were reported in the donor parents. 
When resistance against three rusts were analyzed singly or in combination, the number of completely resistant lines were 99 (30.9\%), 159 (49.7\%) and 227 (70.93\%) for yellow, brown and black rust, respectively. The most of the genotypes mentioned in Table 2 carry some known widely effective $\operatorname{Yr}$ genes like $\operatorname{Yr} 10, \mathrm{Yr} 15, \mathrm{Yr} 24$ singly or in combination. In addition to yellow rust resistance, these lines are resistant to prominent pathotypes of brown and black rusts. Resistance in these lines is likely imparted by a combination of partial resistance genes and some unknown widely effective rust resistance gene/(s) in the background. There is consensus that all types of resistance including partial must be utilized in the development of a breeding strategy to produce cultivars with stable rust resistance (Dyck and Kerber, 1985). These lines are the outcome of selection in segregation generations for yield traits, field-level resistance encompassing adult plant resistance (APR) and ASR. The resistance against yellow rust pathotypes was found in comparatively less number of lines. The resistance proportion against yellow rust is significantly lower (30.9\%) in seedling or ASR as compared to APR where all the 320 were selected for the resistance (score 20MS or less) against yellow rust at Karnal field in the previous generation. It is evident that occurrence of APR is more widespread and the field resistance at adult plant stage is due to both ASR and APR genes. All the 320 genotypes are under further evaluation and selection during rabi season 202021 for the agro-morphological traits, adaptability under different sowing conditions, yield and component traits, field resistance to three rusts and other major biotic and abiotic stresses. Due to spread of new and highly virulent races of Pst particularly, 238S119 (44.1\% of Pst samples) in the large geographical areas of Northern India (Prasad et al., 2020) and Nepal (Gangwar et al., 2021), the number of yellow rust resistant wheat cultivars and materials in breeding lines are expected to decrease. We anticipate that some of the material scored as resistant in 2019-20 may be rendered susceptible to one or the other rust diseases, particularly new pathotypes of yellow rust pathogen. The findings of this experiment suggest that a breeding strategy with screening segregating lines under artificial rust epiphytotic conditions in the breeding field and SRT of advance generation lines for selecting wheat genotypes with resistance against multiple rust pathogen is effective. APR genes individually provide low levels of resistance and combinations of three or more genes are essential to express commercially adequate levels of resistance (Bariana et al., 2017). Marker aided selection in the early generations $\left(\mathrm{F}_{2}\right.$ and $\left.\mathrm{F}_{3}\right)$ for rust resistance genes viz., $\operatorname{Yr} 10$, $\operatorname{Yr} 15, \mathrm{Lr} 24 / \mathrm{Sr} 24$ was carried out to confirm their presence in some of the progenitors of the lines listed in Table 2. The life of effective race-specific ASR genes can be prolonged by using gene combinations as an alternative approach that is being implemented at CIMMYT, to deploy varieties that possess APR based on combinations of minor slow rusting genes (Singh et al., 2014; Rana et al., 2021). Since new pathotypes of rust pathogens are evolving and continuously overcoming the resistance in many popular cultivars, development of new cultivars with durable resistance is need of the hour. Wheat breeders need to focus on accumulating resistance QTLs with additive effect, particularly in combinations with qualitative resistance genes with broad-spectrum resistance.

\section{Conflict of Interest}

Authors declare that they have no conflict of interest.

\section{Ethical Compliance Statement}

NA

\section{Author Contribution}

Conceptualization: $\mathrm{HK}, \mathrm{OPG}, \mathrm{SCB}$; Initial Draft: HK, OPG, SCB, PP, OP, CNM; Critical review and finalization: RK, GK, SK, SSY, PLK, SK, RC and GPS.

\section{References}

1. Anonymous. 2020. Wheat in the world. https://wheat. org/wheat-in-the-world/ (accessed on 30.12.2020.)

2. Anonymous. 2021. Catalogue of Gene Symbols for Wheat. https://wheat.pw.usda.gov/GG3/wgc (Accessed on 29.01.2021)

3. Bariana HS and UK Bansal. 2017. Breeding for disease resistance. In: Encyclopedia of applied plant sciences, vol. 3. Eds. B. Kole, G. B. Murray and J. D. Murphy (Waltham, MA: Academic Press). pp. 69-76.

4. Bhardwaj SC, P Prasad, OP Gangwar, H Khan and S Kumar. 2016. Wheat rust research-then and now. Indian Journal of Agricultural Sciences 86(10): 1231-1244.

5. Bhardwaj SC. 2013. Puccinia -Triticum interaction: an update. Indian Phytopathology 66(1): 14-19. 
6. Chen X. 2005. Epidemiology and control of stripe rust (Puccinia striiformisf. sp. tritici) on wheat. Canadian Journal of Plant Pathology 27(3): 314-337.

7. Dyck PL and ER Kerber. 1985. Resistance of the racespecific type. In Diseases, distribution, epidemiology, and control. Academic Press. pp. 469-500.

8. Gangwar OP, S Kumar, SC Bhardwaj, PL Kashyap, P Prasad and H Khan. 2019. Characterization of three new $\mathrm{Yr} 9$-virulences and identification of sources of resistance among recently developed Indian bread wheat germplasm. Journal of Plant Pathology 101(4): 955-963. http://doi.org/10.1007/s42161-019-00302-w

9. Gangwar OP, P Prasad, Subodh Kumar, Charulata, Sneha Adhikari and SC Bhardwaj. 2020. Mehtaensis 41(1):18.

10. Kaur G, P Srivastava, A Sharma, NS Bains and VS Sohu. 2016. Development of wheat lines carrying stripe rust resistance genes $\operatorname{Yr} 10$ and $\operatorname{Yr} 15$ in productive genetic backgrounds. Journal of Wheat Research 8(2):26-30.

11. Khan H, SC Bhardwaj, OP Gangwar, P Prasad, PL Kashyap, S Savadi, S Kumar and R Rathore. 2017. Identifying some additional rust resistance genes in Indian wheat varieties using robust markers. Cereal Research Communications 45(4): 633-646.

12. Kumar S, SC Bhardwaj, OP Gangwar, A Sharma, N Qureshi, VV Kumaran, H Khan, P Prasad, H Miah, GP Singh and K Sharma. 2021. Lr80: A new and widely effective source of leaf rust resistance of wheat for enhancing diversity of resistance among modern cultivars. Theoretical and Applied Genetics. https://doi. org/10.1007/s00122-020-03735-5

13. McIntosh RA, J Dubcovsky, WJ Rogers, C Morris and XC Xia. 2017. Catalogue of Gene Symbols for Wheat: 2017 Supplement. In: KOMUGI-Integrated Wheat Science Database.http://shigen.nig.ac.jp/ wheat/komugi/genes/macgene/supplement2017.pdf (accessed on January 29, 2021)

14. McIntosh RA, J Dubcovsky, WJ Rogers, XC Xia and WJ Raupp. 2020. In: Catalogue of gene symbols for wheat: 2020 supplement: https://wheat.pw.usda. gov/GG3/sites/default/files/Catalogue $\% 20$ of $\% 20$ Gene $\% 20$ Symbols $\% 20$ for $\% 20$ Wheat $\% 20-\% 20$ supplement2020.pdf (accessed on January 29, 2021)

15. Oliver RPA. 2014. Reassessment of the risk of rust fungi developing resistance to fungicides. Pest Management Science 70(11):1641-1645.

16. Prasad P, SC Bhardwaj, H Khan, OP Gangwar, S Kumar and SB Singh. 2016. Ug99: saga, reality and status. Current Science 110(9):1614-1616.

17. Prasad P, OP Gangwar, S Kumar and SC Bhardwaj. 2020. Mehtaensis 40(2):29.

18. Rana M, R Kaldate, SU Nabi, SH Wani and H Khan. 2021. Marker-Assisted Breeding for Resistance Against Wheat Rusts. In: Physiological, Molecular, and Genetic Perspectives of Wheat Improvement. (Springer, Cham). pp. 229-262.

19. Riaz A, S Periyannan, E Aitken, et al., 2016. A rapid phenotyping method for adult plant resistance to leaf rust in wheat. Plant Methods 12:17 https://doi. org/10.1186/s13007-016-0117-7

20. Singh RP, S Herrera-Foessel, J Huerta-Espino, S Singh, S Bhavani, C Lan and BR Basnet. 2014. Progress towards genetics and breeding for minor genes based resistance to Ug99 and other rusts in CIMMYT high-yielding spring wheat. Journal of Integrative Agriculture 13(2): 255-61.

21. Stakman EG, DM Stewart and WQ Loegering. 1962. Identification of physiological races of Puccinia graminis var. tritici. US Department of Agriculture, ARS E617, pp. 53. 